\title{
ROTOR DYNAMICS AND STATOR VIBRATIONS OF A NOVEL IPM SYNCHRONOUS MOTOR
}

\begin{abstract}
This paper presents the rotor-dynamical computations of a technology demonstrator of an interior permanent magnet (IPM) synchronous motor designed at the Research and Technology Center of Siemens AG within the framework of the European-funded project called MotorBrain. The computations were split into parts consisting of modal and harmonic analyses performed numerically using FEM algorithms and the post-processing estimation of the amplitudes of rotor displacement and velocity within the whole range of a motor's rotation speed. The authors determined modal damping ratios and found resonance frequencies. In a further step, forces were applied to the rotor in order to determine the oscillation amplitudes of points placed along the rotor's geometrical axis (in the cases of both mechanically- and electromagnetically-excited rotors). The computations were performed for the excitation of the first and second flexural vibration mode. Except for rotor-dynamical computations, the authors performed vibration analyses of the stator along with the motor housing. The stator resonance frequencies and their modal deformation shapes were determined. In a further step, electromagnetic forces acting on the stator teeth were numerically found. These forces were then applied to each stator tooth in order to perform harmonic vibration analyses in an attempt to determine the spatial average velocity of the motor housing circumference area.
\end{abstract}

Keywords: rotor-dynamics, synchronous motor, electromagnetic excitation, stator vibrations

\section{ANALIZY DYNAMICZNE SYNCHRONICZNEGO SILNIKA ELEKTRYCZNEGO}

$W$ artykule przedstawiono dynamike wirnika prototypu pewnego silnika elektrycznego zaprojektowanego $w$ Centrum Badań Naukowych $i$ Technologii firmy Siemens $A G, w$ ramach projektu MotorBrain wspólfinansowanego ze środków Unii Europejskiej. Obliczenia zostały podzielone na analizę modalna i harmoniczną. Obliczenia przeprowadzono numerycznie, $z$ wykorzystaniem algorytmów metody elementów skończonych. Znaleziono amplitudy drgań i prędkości drgań wirnika oraz przedstawiono je $w$ funkcji prędkości obrotowej. Autorzy obliczyli wartości thumienia modalnego oraz częstotliwości rezonansowe. W kolejnym kroku obliczono amplitudy drgań punktów wirnika położonych na osi obrotu, dla przypadku wzbudzenia go siłami mechanicznymi i elektromagnetycznymi. Poza dynamika wirnika autorzy przeprowadzili analizy drgań statora wraz z obudowa silnika. Za pomoca algorytmów numerycznych zostały wyznaczone częstotliwości rezonansowe statora oraz kształty jego modalnych deformacji. W kolejnym kroku znaleziono sity elektromagnetyczne działajace na zęby statora. Sity te zostały użyte do wzbudzenia statora i przeprowadzenia analiz harmonicznych, w celu obliczenia uśrednionej prędkości drgań powierzchni obudowy silnika.

Słowa kluczowe: dynamika, wirnik, silnik synchroniczny, wzbudzenie elektromagnetyczne, wibracje stojana

\section{INTRODUCTION}

The object of investigation is a first-technology demonstrator of a multiphase triple-star IPM synchronous motor with ferrite magnets designed at the Research and Technology Center (CT) of Siemens AG within the framework of the European-funded project MotorBrain (MotorBrain 2016). The project's aim was to investigate and develop sustainable drive train technologies and control concepts for the inherently safe and highly efficient powertrains of the $3^{\text {rd }}$ Electric Vehicle Generation (Brockerhoff et al. 2013). One of the investigation concepts is an 18-slot, 16-pole machine with hard ferrite magnets with a "spoke" arrangement and a maximum mechanical power of $65 \mathrm{~kW}$. The motor was designed to be controlled by a triplex three-phase power converter (nine-phase), but it is also possible to control it in the conventional way - by a three-phase power converter.
In the standard 3-phase configuration, the 18-slot, 16-pole double-layer winding consists of two symmetry units that can be connected either in series or in parallel. Within each symmetry unit of nine slots, each phase is represented by three adjacent coils in series. In the alternative triple-star configuration (see Fig. 1), the three neighboring coils are separately supplied by three different inverters. The resulting nine phases are grouped into three 3 -phase systems denoted by indices 1, 2, and 3 . To realize a high motor redundancy, the three systems have no common star point; however, each system has its own isolated star point. The rotor rotational speed $\omega_{m}$ ranges from 0 to 11,500 revolutions per minute (rpm). As the modal analysis will show, the resulting electromagnetic forces acting on the rotor are able to excite several different vibration modes. These forces are caused by the inhomogeneous distribution of the electromagnetic pressure over the rotor circumference.

\footnotetext{
* Siemens AG, Corporate Technology, Research \& Technology Center, Erlangen, Germany; e-mail: robert.goraj@siemens.com, aristide.spagnolo@siemens.com
} 


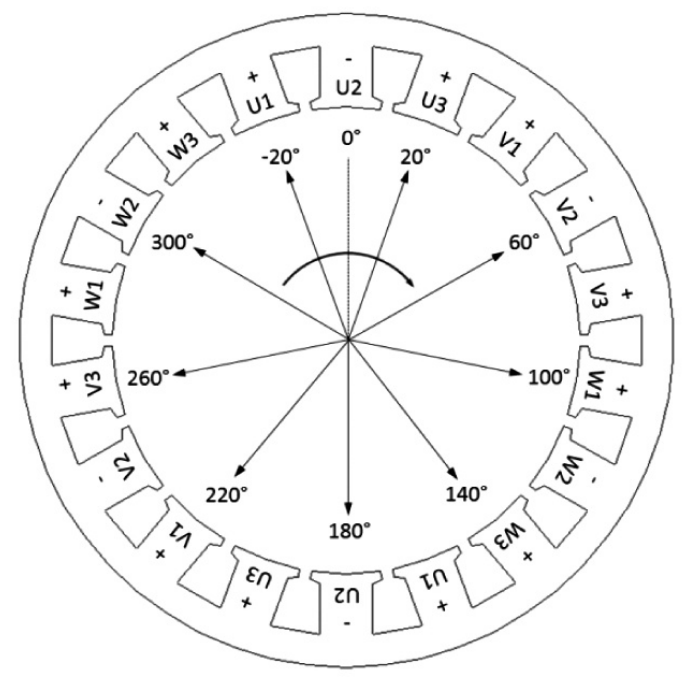

Fig. 1. Cross section of stator with coil numbering and aligned phasors of the shifted nine-phase system

The reason for the inhomogeneous distribution lies mainly in the mechanical tolerances, which result in the rotor eccentricity respective to the stator. This eccentricity (even in the case of a perfectly balanced mechanical shaft) results in electromagnetic imbalance. The dynamical analyses presented in this paper will be split into two separate parts: Part 1) analysis of rotor vibrations; and Part 2) analysis of stator/housing vibrations. Each of these parts will be further split into modal and harmonic analyses. The inputs to the harmonic analyses are numerically computed magnetic forces. These electromagnetic forces will be analyzed in the frequency domain by FFT and 2D FFT algorithms. A similar approach has also been applied by other authors and research groups; e.g., (Arata et al. 2012, Rahman et al. 2011, Pellerey et al. 2012). The vibration spectrum of PM motors with different slot/pole number combinations has been compared, and the dominant modal shape has been identified (Zhu et al. 2010). In (Islam \& Husain 2010), it has been verified that the root cause of vibration is the radial electromagnetic force rather than the torque ripple.

\section{OVERVIEW OF THE CONTROL STRATEGY}

The advantages of polyphase machines and systems are well-known and long-established. In electrical machines, the winding factors can be increased and the torque ripple reduced by using multiple phases. Space-harmonics in the air gap flux are also reduced (Miller, McGilp 2009).

The analyzed motor consists of a nine-phase power converter, in which all nine phases are mutually coupled with each other. The phase labelling is: $\mathrm{U}_{1} \mathrm{~V}_{1} \mathrm{~W}_{1}, \mathrm{U}_{2} \mathrm{~V}_{2} \mathrm{~W}_{2}$, $\mathrm{U}_{3} \mathrm{~V}_{3} \mathrm{~W}_{3}$. The rotor $d$-axis is at angle $\theta$ relative to the axis

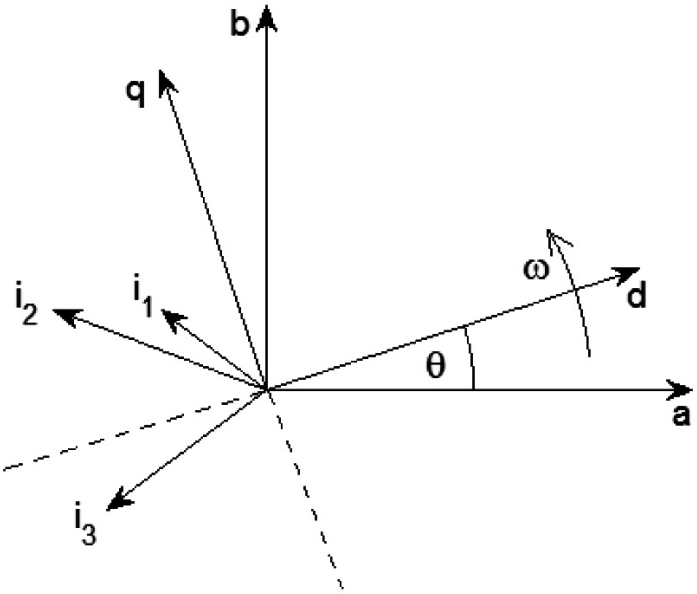

Fig. 2. Current space phasor

of phase $\mathrm{U}_{2}$. The $q$-axis leads the $d$-axis by $\pi / 2$ electrical radians (see Fig. 2). The $d q$-transformation applied to all three windings sets gives:

$$
\begin{aligned}
& v_{d j}=\dot{\Psi}_{d j}+R_{j} i_{d j}-\Psi_{q j} p \omega_{m} \\
& v_{q j}=\dot{\Psi}_{q j}+R_{j} i_{q j}+\Psi_{d j} p \omega_{m}
\end{aligned}
$$

where $v_{d}, v_{q}, i_{d}, i_{q}$ are $d$ and $q$ voltages and currents, $R$ the resistance of stator windings $p$ - the number of motor pole pairs, and $\omega_{m}$ the mechanical rotation speed of the rotor. The index $j$ in formulas (1) and (2) indicates the set of the winding $(j=1,2,3)$, and the magnetic flux is given by:

$$
\begin{aligned}
& \Psi_{d 1}=i_{d 1} L_{d 1}+i_{d 2} M_{d 1 d 2}+i_{d 3} M_{d 1 d 3}+\lambda \\
& \Psi_{q 1}=i_{q 1} L_{q 1}+i_{q 2} M_{q 1 q 2}+i_{q 3} M_{q 1 q 3} \\
& \Psi_{d 2}=i_{d 2} L_{d 2}+i_{d 1} M_{d 1 d 2}+i_{d 3} M_{d 2 d 3}+\lambda \\
& \Psi_{q 2}=i_{q 2} L_{q 2}+i_{q 1} M_{q 1 q 2}+i_{q 3} M_{q 2 q 3} \\
& \Psi_{d 3}=i_{d 3} L_{d 3}+i_{d 1} M_{d 1 d 3}+i_{d 2} M_{d 2 d 3}+\lambda \\
& \Psi_{q 3}=i_{q 3} L_{q 3}+i_{q 1} M_{q 1 q 3}+i_{q 2} M_{q 2 q 3}
\end{aligned}
$$

Parameter $\lambda$ is the amplitude of the flux induced by permanent magnets of the rotor, $L_{d}$ and $L_{q}$ are $d$ and $q$ self-inductances, and $M_{d d}$ and $M_{q q}$ are the mutual inductance between selected sets of windings. For the mutual inductances, it was assumed that: $M_{d 2 d 1}=M_{d 1 d 2}$, $M_{d 3 d 1}=M_{d 1 d 3}, M_{d 3 d 2}=M_{d 2 d 3}, M_{q 2 q 1}=M_{q 1 q 2}, M_{q 3 q 1}=$ $=M_{q 1 q 3}, M_{q 3 q 2}=M_{q 2 q 3}$. Control of the PM motor is the PI current field-oriented control in the rotor flux fixed co-ordinate system (see Figs. 2 and 3). 


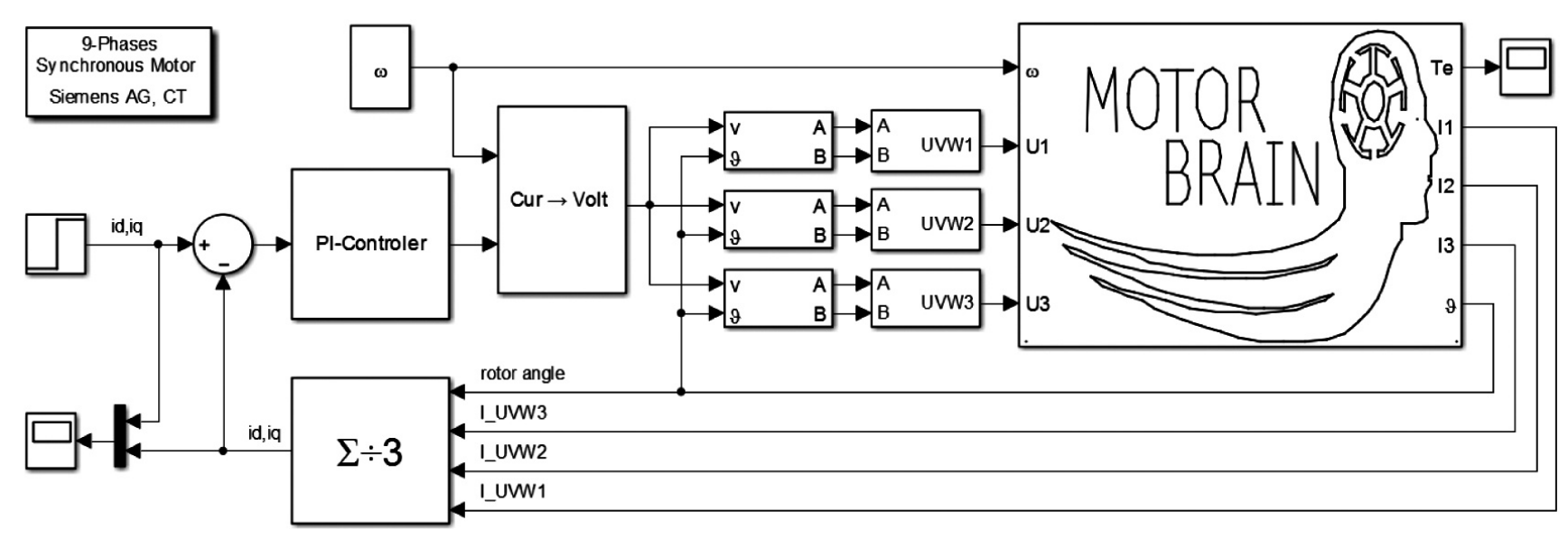

Fig. 3. Model in loop feedback control of investigated PM motor

The control variables are the mean values of $d$ and $q$ currents defined by the following formula:

$$
i_{d, q}=3^{-1} \sum_{j=1}^{j=3} i_{d j, q j}
$$

These mean current values are converted to electrical mean voltages $v_{d}, v_{q}$. Finally, the voltages are transformed into all nine stator voltages: $\mathrm{U}_{1} \mathrm{~V}_{1} \mathrm{~W}_{1}, \mathrm{U}_{2} \mathrm{~V}_{2} \mathrm{~W}_{2}$, $\mathrm{U}_{3} \mathrm{~V}_{3} \mathrm{~W}_{3}$. Voltages $\mathrm{U}_{1} \mathrm{~V}_{1} \mathrm{~W}_{1}$ and $\mathrm{U}_{3} \mathrm{~V}_{3} \mathrm{~W}_{3}$ are rotated in phase by $\phi= \pm \pi / 9$ electrical radians with regard to voltages $\mathrm{U}_{2} \mathrm{~V}_{2} \mathrm{~W}_{2}$. The three-phase power control can be realized by setting value $\varphi$ to zero electrical radians. The electrical torque can be computed by:

$$
T=3 / 2 p \sum_{j=1}^{j=3} T_{j}
$$

Parameter $p$ in formula (10) is (as previously mentioned) the number of motor pole-pairs that, for the analyzed motor, is equal to $p=8$. For the electric torques one has the following expressions:

$$
\begin{aligned}
T_{1} & =i_{q 1} \lambda+\left(L_{d 1}-L_{q 1}\right) i_{d 1} i_{q 1}+M_{d 1 d 2} i_{d 2} i_{q 1}+ \\
& +M_{d 1 d 3} i_{d 3} i_{q 1}-M_{q 1 q 2} i_{q 2} i_{d 1}-M_{q 1 q 3} i_{q 3} i_{d 1}
\end{aligned}
$$

$$
\begin{aligned}
T_{2} & =i_{q 2} \lambda+\left(L_{d 2}-L_{q 2}\right) i_{d 2} i_{q 2}+M_{d 1 d 2} i_{d 1} i_{q 2}+ \\
& +M_{d 2 d 3} i_{d 3} i_{q 2}-M_{q 1 q 2} i_{q 1} i_{d 2}-M_{q 2 q 3} i_{q 3} i_{d 2} \\
T_{3} & =i_{q 3} \lambda+\left(L_{d 3}-L_{q 3}\right) i_{d 3} i_{q 3}+M_{d 1 d 3} i_{d 1} i_{q 3}+ \\
& +M_{d 2 d 3} i_{d 2} i_{q 3}-M_{q 1 q 3} i_{q 1} i_{d 3}-M_{q 2 q 3} i_{q 2} i_{d 3}
\end{aligned}
$$

\section{ROTOR CRITICAL SPEED MAP}

The modal analysis was performed numerically using the FE Method. A 2D axisymmetric model of the rotor (the cross section of which is shown in Figure 4) was created and computed by Ansys 14.0.0. This model makes use of the Ansys element: SOLID272. The density of steel A in the model was equal to $7850 \mathrm{~kg} / \mathrm{m}^{3}$. The approximation of the real rotor geometry with a full cylinder leads to a mean density of steel $\mathrm{B}$, set to $6392.6 \mathrm{~kg} / \mathrm{m}^{3}$. The elasticity module of steel A and steel B is equal to $200 \mathrm{GPa}$. The total mass of all rotating components equals $21.9 \mathrm{~kg}$, and the length of the shaft equals $386 \mathrm{~mm}$. The rotor with the $149-\mathrm{mm}$ diameter was placed on rolling contact bearings. The distance between bearings equals $263 \mathrm{~mm}$.

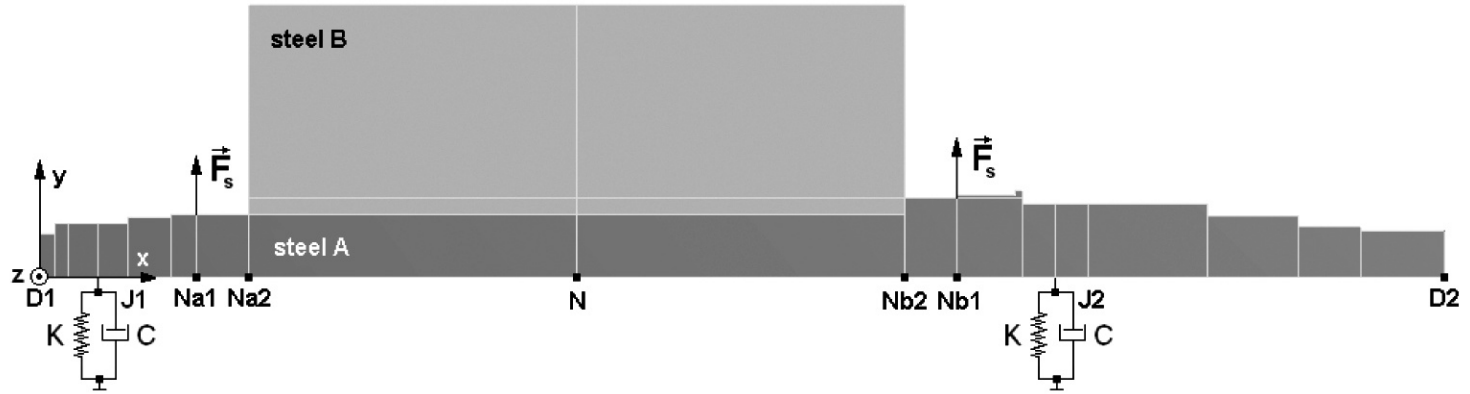

Fig. 4. Rotor longitudinal cross with unbalanced excitation forces 
a)

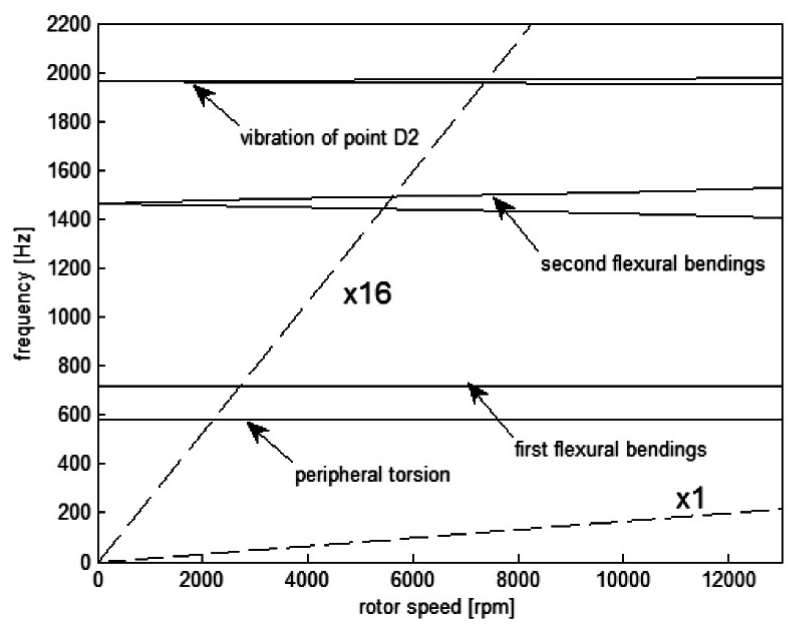

b)

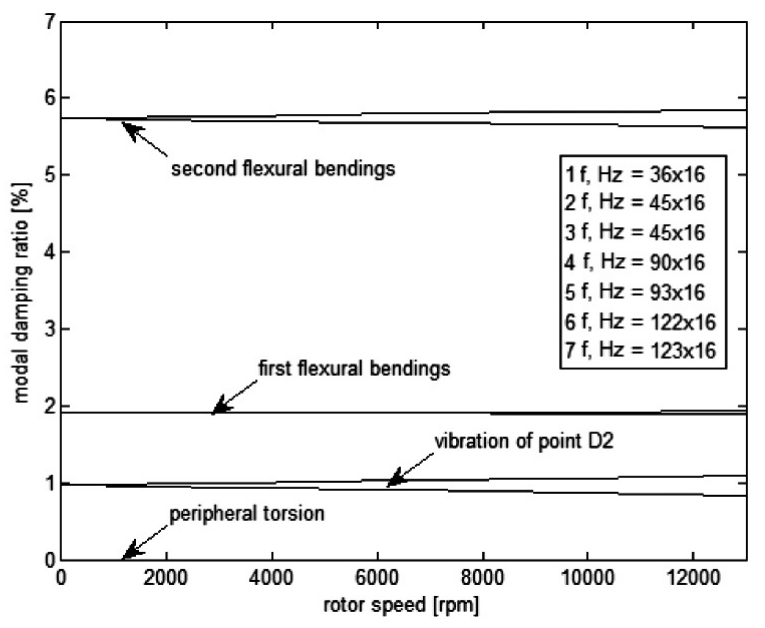

Fig. 5. Campbell diagram (a) and modal damping ratios (b)

The bearing stiffness and damping were assumed to be independent of the radial pressure and isotropic. The stiffness was set to the constant value of $K_{y y}=K_{z z}=0.5 \mathrm{GN} / \mathrm{m}$ and the damping to $C_{y y}=C_{z z}=10 \mathrm{kNs} / \mathrm{m}$. These values are reference-free internal "a priori" assumptions of Siemens AG in the tensed-up condition of the bearing used. In the performed modal analysis, gyroscopic forces and the spin-softening effect were taken into account. The modal analysis was performed in the whole range of rotor rotational speeds (i.e., from 0 to $11,500 \mathrm{rpm}$ ). The solution of the modal analysis by means of resonance frequencies and modal damping ratios are shown in Figure 5.

The deformation forms of the modes are the following:

- No. 1: peripheral torsion at $576 \mathrm{~Hz}$,

- No. 2: first flexural bending at $720 \mathrm{~Hz}$ backward case,

- No. 3: first flexural bending at $720 \mathrm{~Hz}$ forward case,

- No. 4: second flexural bending at $1440 \mathrm{~Hz}$ backward case,

- No. 5: second flexural bending at $1488 \mathrm{~Hz}$ forward case,

- No. 6: vibration of point D2 at $1952 \mathrm{~Hz}$ backward case,

- No. 7: vibration of point D2 at $1968 \mathrm{~Hz}$ forward case.

The dashed line on the Campbell diagram signed with $x 1$ symbolizes the excitation frequency of the mechanical unbalance of the rotor that is equal to $f_{m}=\omega_{m}(2 \pi)^{-1}$. The other dashed line on the diagram signed with $x 16$ symbolizes the excitation frequency of the electromagnetic unbalance force, which is (in the case of motor pole-pair-number $p=8$ ) 16 times higher than frequency $f_{m}$. As can be seen in Figure 5, the mechanical unbalance cannot cause the resonance of any rotor modes in the considered range of the rotational speed. This is different for the electromagnetic force - its frequency is high enough to excite the resonance of several vibration modes. The first flexural bending is almost independent of the rotational speed of the rotor. Lines 2 and 3 lie almost on top of one another, with the chosen scaling of the y-axis.

The modal damping ratio of this mode is equal to $1.9 \%$. The best-damped mode is the second flexural bending of the rotor (see Fig. 5). The modal damping ratio of this mode is equal to $5.7 \%$. Because no damping was set in the computation model, the worst-damped mode is the peripheral torsion of the rotor. The modal damping ratio of this mode is equal to zero. Because peripheral torsion can be excited, for example, by the torque waviness of the motor but cannot be excited either by mechanical unbalance nor by the radial component of the electromagnetic force, this kind of vibration will not be a matter of further consideration. The vibration of point D2 will be only partially investigated in the analysis. It influences vibrations of points placed between the bearings.

\section{MECHANICALLY EXCITED ROTOR VIBRATIONS}

In the first step, a harmonic analysis was performed in the case of purely mechanical unbalance. The harmonic analysis was performed under the worst-case scenario; that is, in the case of an overestimated mechanical unbalance. The unbalance of $f_{b}=280 \mathrm{~g} \cdot \mathrm{mm}$ was obtained in the case of balancing with quality G16. Half of this value was set as an input to the harmonic analysis on two balancing points $\mathrm{Na} 1$ and $\mathrm{Nb} 1$ (see Fig. 4). Excitation force $\mathbf{F}_{b}$ can be defined in this case by the following formula:

$$
\mathbf{F}_{b}=2^{-1} \omega_{m}^{2} f_{b}\left[\cos \left(n \omega_{m} t\right) \mathbf{e}_{y}+\sin \left(n \omega_{m} t\right) \mathbf{e}_{z}\right]
$$


The post-processing evaluation was restricted to points placed along the rotor's geometrical axis between $\mathrm{Na} 2$ and $\mathrm{Nb} 2$ (see Fig. 4). The output of the harmonic analysis are complex values of deformations $\underline{u}_{y}\left(\omega_{m}, x\right)$ and $\underline{u}_{z}\left(\omega_{m}, x\right)$. One can use these values in order to compute the excitation-frequency-dependent spatial distribution of rotor displacement amplitudes and their maximum values according to:

$$
\begin{aligned}
& u_{y}\left(\omega_{m}, x\right)=\sqrt{\underline{u}_{y}\left(\underline{u}_{y}\right)^{*}}, \hat{u}_{y}=\max \left\{u_{y}\left(\omega_{m}, x\right)\right\} \\
& u_{z}\left(\omega_{m}, x\right)=\sqrt{\underline{u}_{z}\left(\underline{u}_{z}\right)^{*}}, \hat{u}_{z}=\max \left\{u_{z}\left(\omega_{m}, x\right)\right\}
\end{aligned}
$$

The asterisk in formulas (15) and (16) was used to indicate the conjugate complex value of deformations $\underline{u}_{y}\left(\omega_{m}, x\right)$ and $\underline{u}_{z}\left(\omega_{m}, x\right)$. The rotor displacement amplitudes were used to estimate the excitation-frequency-dependent spatial distribution of rotor velocity amplitudes and their maximum values according to:

$$
\begin{aligned}
& v_{y}\left(\omega_{m}, x\right)=\omega_{m} u_{y}\left(\omega_{m}, x\right), \hat{v}_{y}=\max \left\{v_{y}\left(\omega_{m}, x\right)\right\} \\
& v_{z}\left(\omega_{m}, x\right)=\omega_{m} u_{z}\left(\omega_{m}, x\right), \hat{v}_{z}=\max \left\{v_{z}\left(\omega_{m}, x\right)\right\}
\end{aligned}
$$

As a result, the obtained maximum values of displacement amplitudes were equal to $\hat{u}_{y}=\hat{u}_{z}=0.9 \mu \mathrm{m}$. The maximum values of the velocity amplitudes were equal to $\hat{v}_{y}=\hat{v}_{z}=1 \mathrm{~mm} / \mathrm{s}$. As further analyses will show, these values are small compared to the values computed in the case of excitation caused by electromagnetic force and can be neglected in the first approximation.

\section{MAGNETICALLY EXCITED ROTOR VIBRATIONS}

The resulting electromagnetic force in the rotor was numerically computed with the Virtual Work Method by Finite Element electromagnetic software Maxwell 2D V16. In the simulation, only the static eccentricity of the rotor axis was taken into consideration. This means that the rotor rotates around its geometrical axis (which is not centered in the stator bore). The machine was supplied with a current of $100 \mathrm{~A}$ (rms) in each three-phase inverter and a slight field weakening corresponding to the maximal produced torque (short time). The computation point was set to a speed of $3600 \mathrm{rpm}$ and to the maximum mechanical power. A parameterization was performed in order to simulate displacement from 0 up to $150 \mu \mathrm{m}$ in the y-direction.

The results for these working conditions are summarized in the diagram in Figure 6a. In Figure $6 \mathrm{~b}$ the angular evolution of the forces acting on the rotor for a rotor eccentricity of $150 \mu \mathrm{m}$ is shown. For the following harmonic analysis, this worst condition $(150 \mu \mathrm{m})$ was considered. The force was set to the harmonic analysis as the electromagnetic imbalance according to formula (19). For simplification reasons, the force was not distributed over the whole rotor but simply attached this time to points $\mathrm{Na} 2$ and $\mathrm{Nb} 2$ (see Fig. 4).

$$
\underline{F}_{m}=F_{y}+i F_{z}=2^{-1} F_{m a g} \exp \left(i 2 p \omega_{m} t\right)
$$

a)

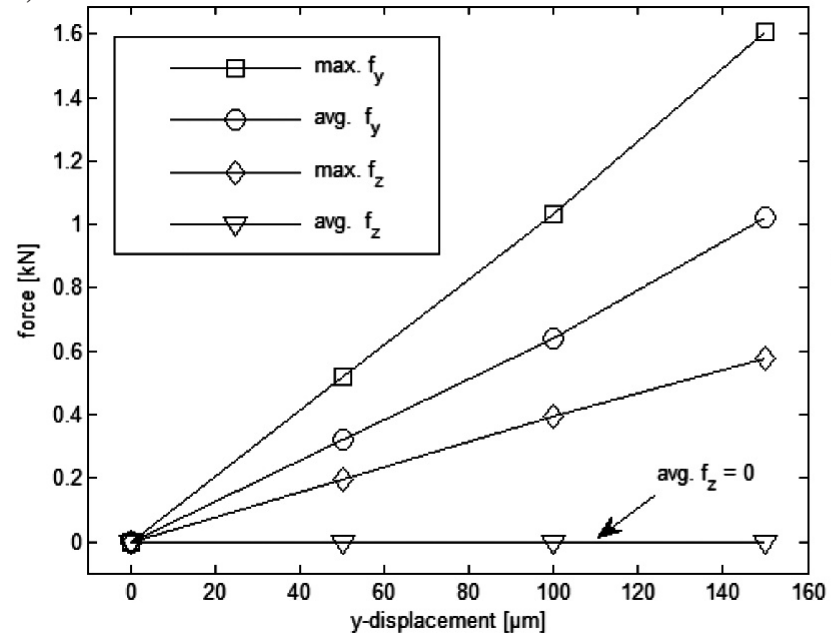

b)

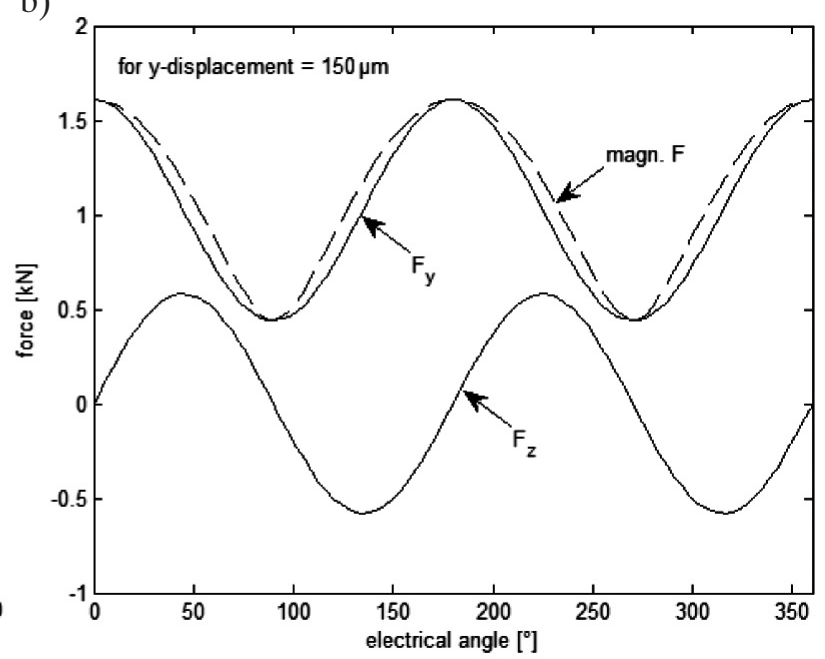

Fig. 6. Maximum and average forces acting on rotor with different values of static eccentricity (a) and angular evolution of forces acting on rotor with eccentricity of $150 \mu \mathrm{m}$ (b) 
The value $F_{m a g}$ in formula (19) equals to $581 \mathrm{~N}$. The excitation-frequency-dependent spatial distribution of velocity amplitudes in the case of electromagnetic excitation are defined by formulas (20) and (21).

$$
\begin{aligned}
& v_{y}\left(\omega_{m}, x\right)=2 p \omega_{m} u_{y}\left(\omega_{m}, x\right) \\
& v_{z}\left(\omega_{m}, x\right)=2 p \omega_{m} u_{z}\left(\omega_{m}, x\right)
\end{aligned}
$$

These values were again computed using formulas (15) and (16). Harmonic analyses were performed for excitation frequencies ranging from $0 \mathrm{~Hz}$ to $3200 \mathrm{~Hz}$ with a computation step of $8 \mathrm{~Hz}$. The computed distribution of displacement and velocity amplitudes were plotted as a function of excitation frequency $2 p f_{m}$ in Figure 7. The vertical dashed lines in the figure lie on the resonance frequencies previously computed by the modal analysis. There is a relatively good match between the frequency for which the maximum of the vibration amplitudes occurs in the case of harmonic computation and the resonance frequency that was found using the modal analysis. The difference between these fre- quencies is less than one percent. The maximum values of displacement amplitudes are equal to $\hat{u}_{y}=\hat{u}_{y}=19.3 \mu \mathrm{m}$. The maximum values of velocity amplitudes are equal to $\hat{v}_{y}=\hat{v}_{z}=87.2 \mathrm{~mm} / \mathrm{s}$. In the next step, harmonic analysis was performed in the case of an electromagnetic tilt simulating an opposite eccentricity direction for the two extremities of the shaft. The previously computed value of $F_{\text {mag }}$ was halved and again attached to points $\mathrm{Na} 2$ and $\mathrm{Nb} 2$.

In order to simulate the different eccentricity, the force set to point $\mathrm{Nb} 2$ was rotated in a peripheral direction by $180^{\circ}$.

$$
\begin{aligned}
& \underline{F}_{m}^{a}=2^{-1} F_{m a g} \exp \left(i 2 p \omega_{m} t\right) \\
& \underline{F}_{m}^{b}=2^{-1} F_{m a g} \exp \left(i 2 p \omega_{m} t+\pi\right)
\end{aligned}
$$

The force set to point $\mathrm{Na} 2$ is defined by formula (22), and the force set to point $\mathrm{Nb} 2$ is defined by formula (23). Computed displacement amplitudes and velocity amplitudes in the case of electromagnetic tilt were plotted in Figure 8.

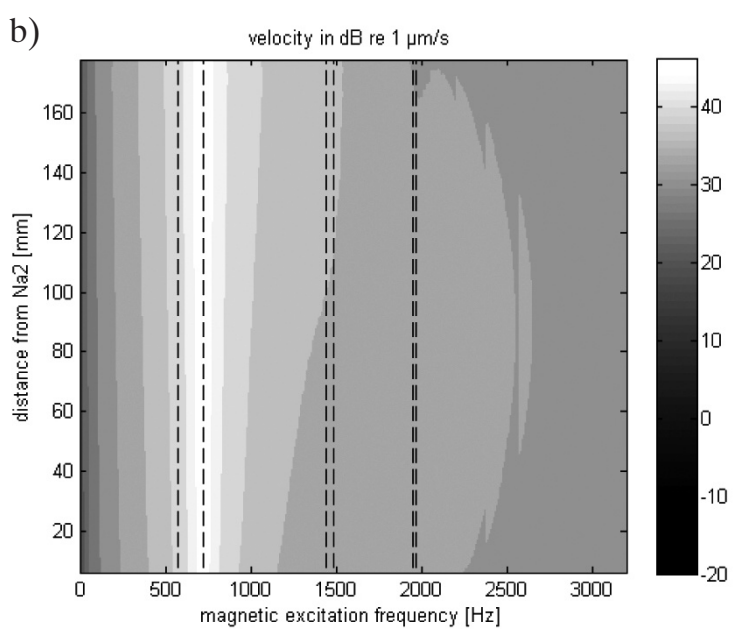

Fig. 7. Rotor displacement amplitudes (a) and velocity amplitudes caused by radial electromagnetic pull (b)

a)

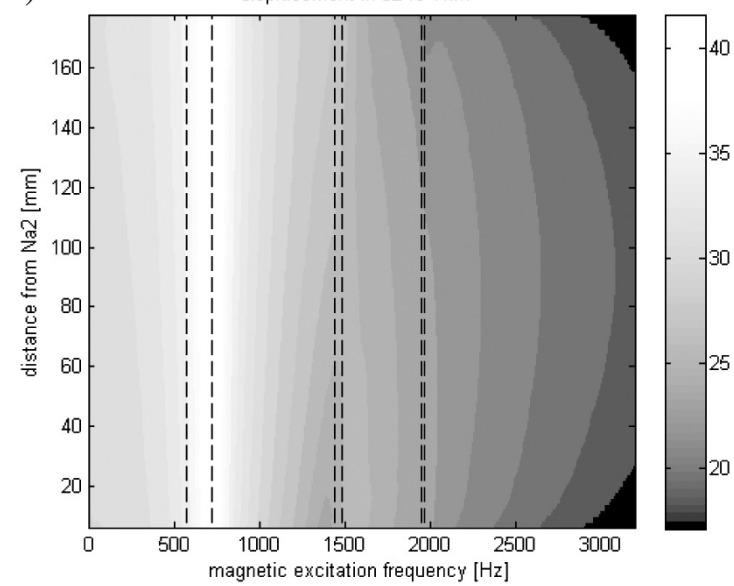

a)

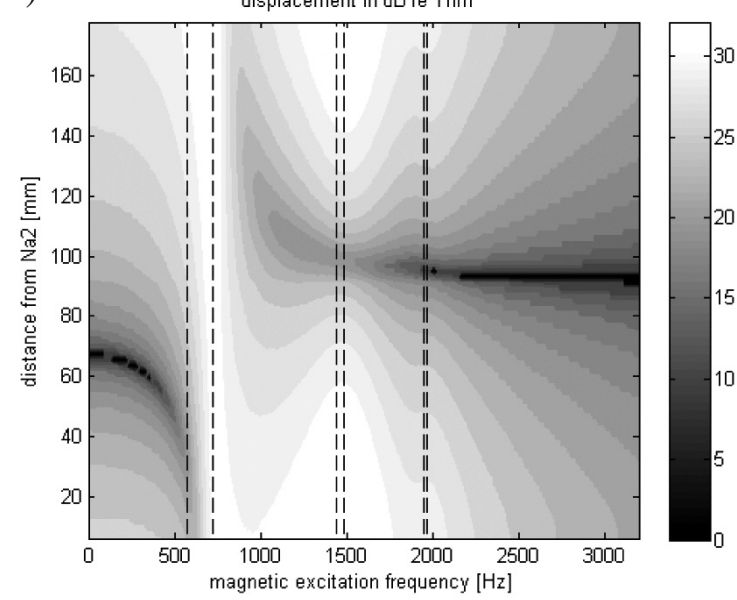

b)

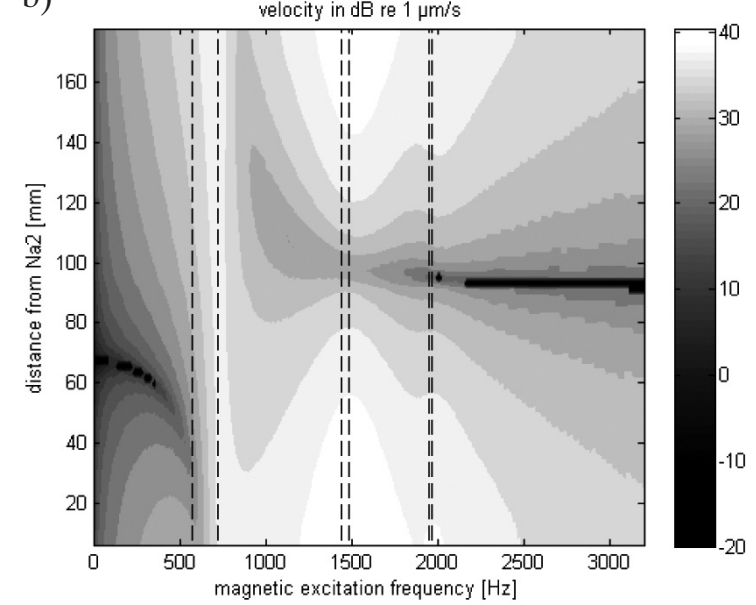

Fig. 8. Rotor displacement amplitudes (a) and velocity amplitudes caused by electromagnetic tilt imbalance (b) 
In the graphic, one can see several local maxima. Electromagnetic tilt excited the first and second flexural bending mode and the vibration of point D2. Also in this computation case, there is a relatively good match between the frequencies for which the maxima of vibration amplitudes occur in harmonic computation and the resonance frequencies that were found using the modal analysis. The difference between these frequencies in the case of electromagnetic tilt is still less than one percent. The maximum values of displacement amplitudes are equal to $\hat{u}_{y}=\hat{u}_{y}=2.4 \mu \mathrm{m}$. The maximum values of velocity amplitudes equal $\hat{v}_{y}=\hat{v}_{z}=22.2 \mathrm{~mm} / \mathrm{s}$.

\section{MODAL ANALYSIS OF STATOR VIBRATIONS}

The modal analysis was performed numerically using the FE Method. A 3D model consisting of a stator, housing, and coils was created and computed in Ansys 14.0.0. The density of the coils was set to $5350 \mathrm{~kg} / \mathrm{m}^{3}$, and the density of the stator was set to $7850 \mathrm{~kg} / \mathrm{m}^{3}$. The elasticity module of the winding was approximated to be equal to the elasticity module of pure copper and was specified in the FE model to be equal to $100 \mathrm{GPa}$. The E-module of the stator was set to $200 \mathrm{GPa}$. The thickness of the motor housing made of an aluminum alloy was averaged to $9.9 \mathrm{~mm}$.

The results of the modal analysis in terms of resonance frequencies and deformation forms are listed below and shown in Figure 9.

- Mode 0,1: $8083 \mathrm{~Hz}$ (radial deformation (radial "pumping")),

- Mode 2,1: $4983 \mathrm{~Hz}$ symmetric, $4989 \mathrm{~Hz}$ anti-symmetric,

- Mode 3,1: $7260 \mathrm{~Hz}$ symmetric, $7263 \mathrm{~Hz}$ anti-symmetric,

- Mode 4,1: $10789 \mathrm{~Hz}$ symmetric, $10793 \mathrm{~Hz}$ anti-symmetric,

- Mode 1,0 (b): first axial bending vibration, $4692 \mathrm{~Hz}$ symmetric, $4695 \mathrm{~Hz}$ anti-symmetric (not shown),

- Mode (t): peripheral torsional vibration $5771 \mathrm{~Hz}$ (not shown).

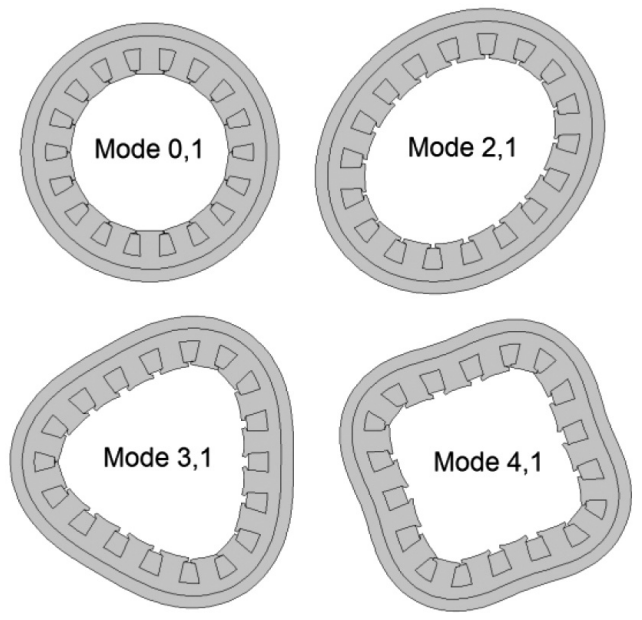

Fig. 9. Selected modal deformation shapes

\section{COMPUTATION METHOD \\ FOR DETERMINING TRANSIENT \\ ELECTROMAGNETIC FORCES}

Inputs of the harmonic analysis are the electromagnetic force and torque, computed numerically with Finite Element electromagnetic software Maxwell 2D V16.

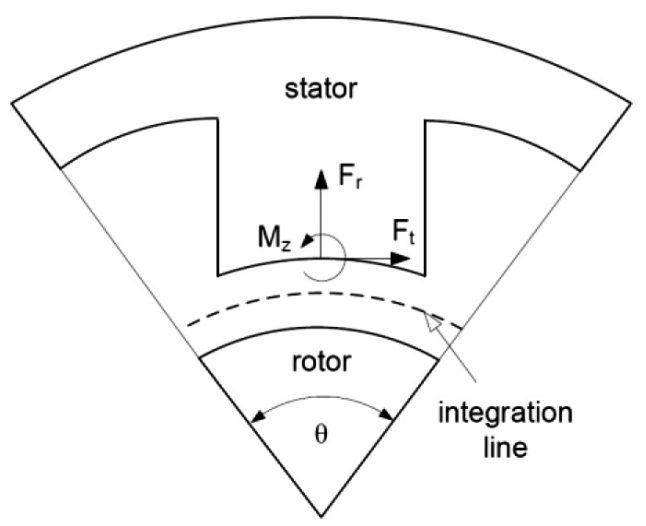

Fig. 10. Tooth section and resulting lumped electromagnetic force and moment acting on tooth

Considering the teeth of the stator as a single rigid body (see Fig. 10), the components of the magnetic flux density can be integrated along a line lying in the middle of the air gap at radius $R$ (spanning the width of a tooth section) and multiplied by stack length $L_{s}$. As a result, one can obtain the lumped radial (24) and tangential (25) components of the electromagnetic force:

$$
\begin{aligned}
& F_{r}(t)=\left(2 \mu_{0}\right)^{-1} R L_{s} \int_{-\theta / 2}^{+\theta / 2}\left(B_{r}^{2}-B_{\tau}^{2}\right) d \theta \\
& F_{\tau}(t)=\mu_{0}{ }^{-1} R L_{s} \int_{-\theta / 2}^{+\theta / 2} B_{r} B_{\tau} d \theta
\end{aligned}
$$

The axial torque component can be estimated using (26):

$$
M_{z}(t) \cong\left(2 \mu_{0}\right)^{-1} R^{2} L_{S} \int_{-\theta / 2}^{+\theta / 2}\left(B_{r}^{2}-B_{\tau}^{2}\right) \theta d \theta
$$

These force and torque components represent the influence of the interaction between the rotor and stator on a single tooth. With a magnetic transient simulation, the time and spatial evolution of the parameters can be calculated for a successive transformation in the frequency domain by a 2D FFT. 


\section{INPUTS OF HARMONIC ANALYSIS OF STATOR VIBRATIONS}

The electromagnetic forces were applied in the harmonic analysis as resulting forces acting on each stator tooth. In the case of no rotor tilt, this force has only the radial and tangential components and can be built as a vector:

$$
\begin{aligned}
& \mathbf{F}_{m}\left(n, f_{m}\right)=\left(f^{r}(n) \cos \left(n \omega_{m} t+\varphi^{r}(n)\right)\right) \mathbf{e}_{r}+ \\
& +\left(f^{\tau}(n) \sin \left(n \omega_{m} t+\varphi^{\tau}(n)\right)\right) \mathbf{e}_{\tau}
\end{aligned}
$$

The force depends on the rotational speed of the rotor $\omega_{m}=2 \pi f_{m}$ and on the time harmonic order $n$. As the distribution of the electromagnetic force is not homogenous along the tooth, one must correct the force by means of torque (28) acting in the middle of each tooth.

$$
\mathbf{M}_{z}\left(n, f_{m}\right)=m^{z}(n) \cos \left(n \omega_{m} t+\varphi^{z}(n)\right) \mathbf{e}_{z}
$$

Amplitudes of harmonic components of the resulting force and torques acting on stator teeth are shown in Figure 11. The frequency of the fundamental wave is 16 times higher 1 than $f_{m}$ since the motor consists of 16 poles.
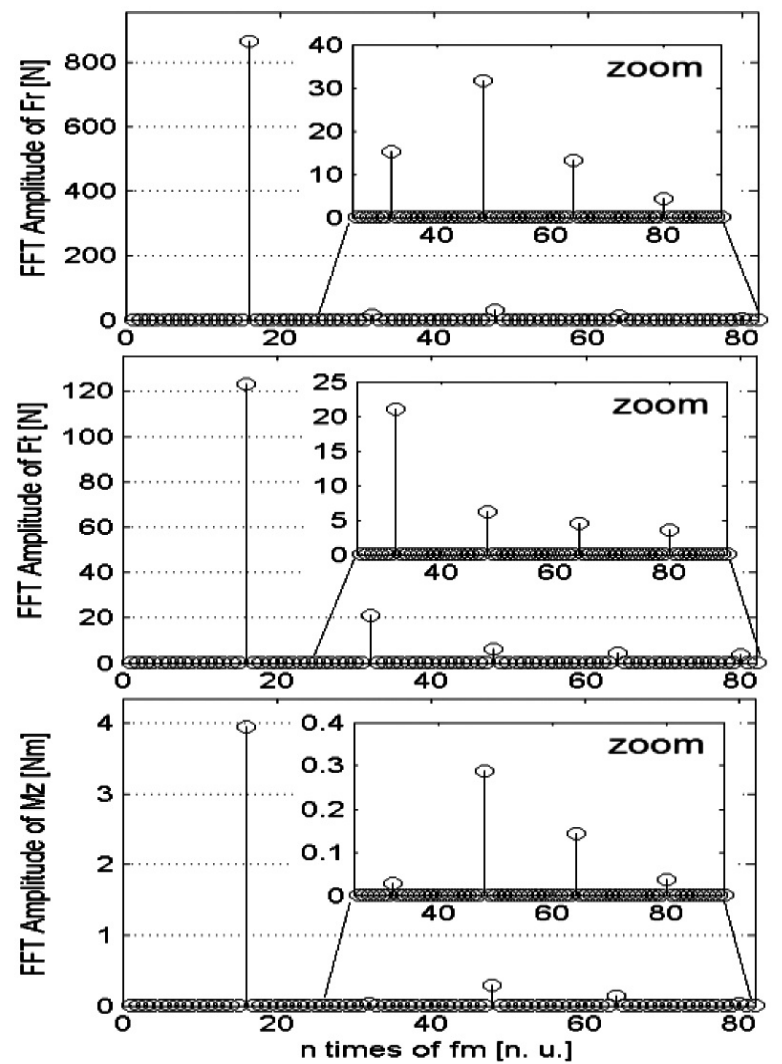

Fig. 11. Amplitudes of harmonic components of resulting force and torque acting on stator teeth
In this computation case, the amplitudes of force and torque are equal for each stator tooth - the excitation is simply time-shifted by $20^{\circ}$. The harmonic content of the radial component of the resulting magnetic force equals $7.1 \%$, and that of the tangential component $24.3 \%$. The harmonic content of the axial component of torque equals $12.5 \%$.

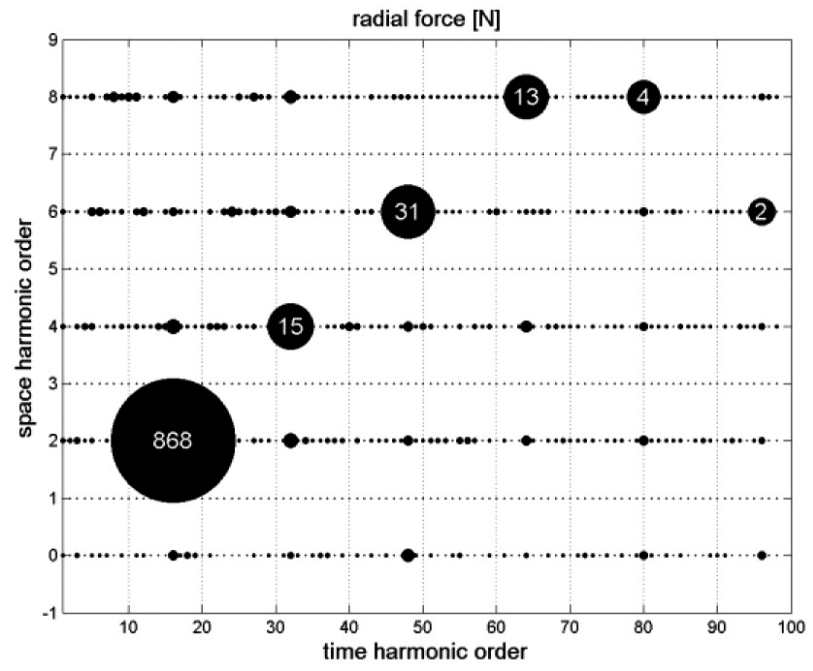

Fig. 12. 2D FFT of radial force

The radial component of the resulting magnetic force is shown in Figure 12 as a discrete function of space- and time-harmonic order. The force of order $(0,0)$ was purposely disabled in the figure, as its influence on the stator vibration is insignificant. One can recognize from the figure that the spatial order of the fundamental wave is equal to two. This value is the greatest common divisor (GCD) between the number of stator slots and the number of poles. The lowest dominant vibration mode order of the considered motor is mode 2,1 (Section 6).

\section{HARMONIC ANALYSIS OF STATOR VIBRATIONS}

The output of the harmonic analysis is the complex radial displacement of points placed on the circumference area of the motor housing $\underline{r}$. These values were used to compute the spectral distribution of the rotor speed-dependent mean amplitude of the radial displacement (29):

$$
\bar{r}\left(n, f_{m}\right)=\left(A^{-1} \sum_{i} \underline{r_{i}} \cdot \underline{r_{i}^{*}} A_{i}\right)^{1 / 2}
$$

The asterisk in formula (29) indicates the complex conjugate value of $\underline{r}$ which is a function depending on 
$n$ and $f_{m}$. Using the complex displacement, one can also compute the mean radial velocity (30) using a summation over the motor housing circumferential area $A$. This area is equal to $0.173 \mathrm{~m}^{2}$.

$$
\bar{v}\left(n, f_{m}\right)=n \omega_{m} \bar{r}\left(n, f_{m}\right)
$$

The logarithmic spectral distribution of mean radial displacement of the motor housing (31) is shown in Figure 13a.

$$
\bar{r}_{\log }\left(n, f_{m}\right)=10 \log \left(\bar{r}\left(n, f_{m}\right) / 1 \mathrm{~nm}\right)
$$

The radial velocity of the motor housing according to formula (32) is shown in Figure 13b.

$$
\bar{v}_{\log }\left(n, f_{m}\right)=10 \log \left(\bar{v}\left(n, f_{m}\right) /(1 \mu \mathrm{m} / \mathrm{s})\right)
$$
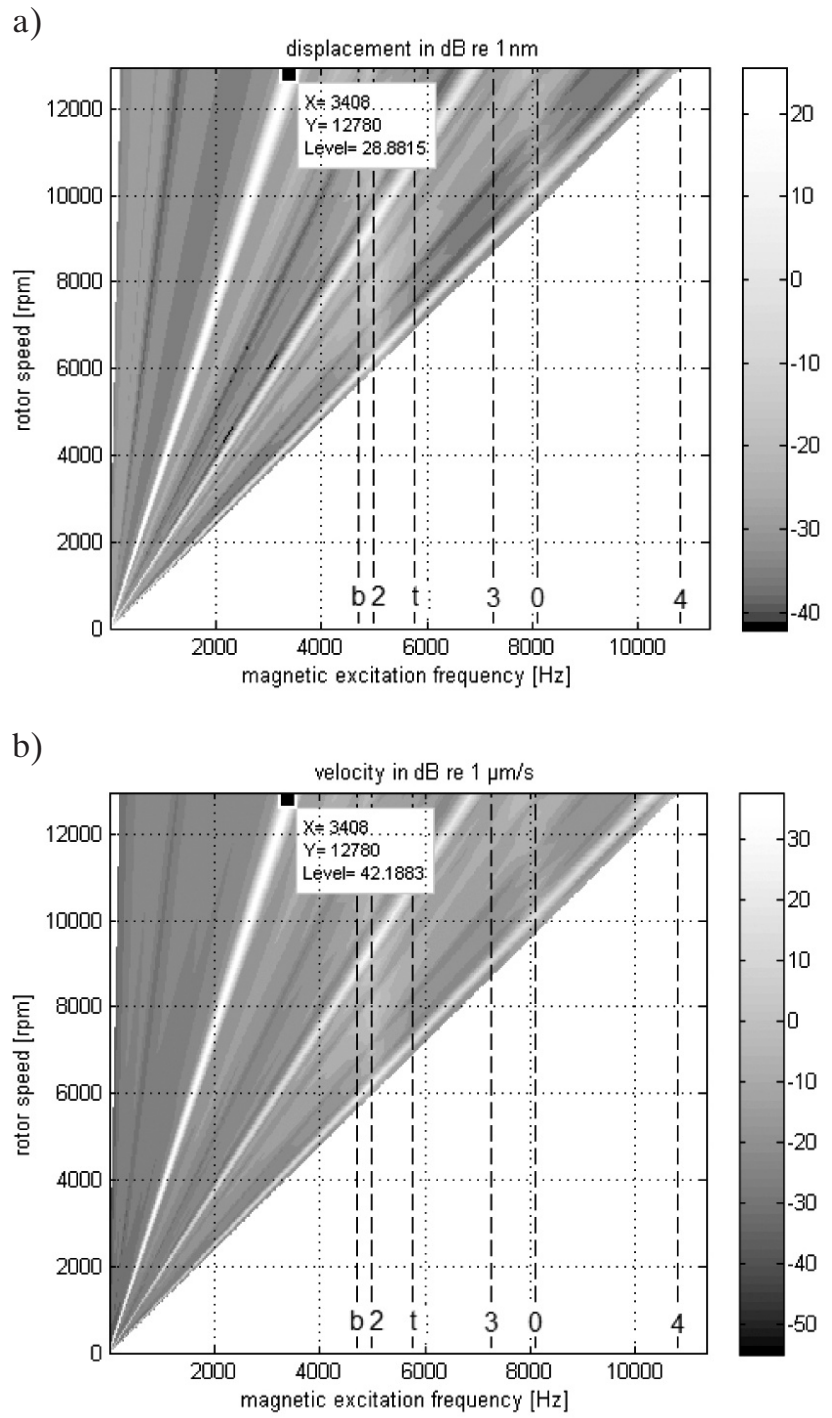

Fig. 13. Spectrogram of radial displacement (a) and radial velocity of motor housing (b)
The computational rotor rotational speed was set to $12,960 \mathrm{rpm}$ - a bit higher than the maximal rotor speed. The maximal amplitude of the radial displacement is equal to $\max \left\{\bar{r}\left(n, f_{m}\right)\right\}=0.79 \mu \mathrm{m}$, and the maximal amplitude of the radial velocity is equal to $\max \left\{\bar{v}\left(n, f_{m}\right)\right\}=17.21 \mathrm{~mm} / \mathrm{s}$.

\section{CONCLUSIONS AND FURTHER COMPUTATIONAL
INVESTIGATION POSSIBILITIES}

The rotor dynamical analyses performed have shown that the frequency of mechanical unbalance is too small to cause vibration resonance of the investigated rotor. The analyses revealed, however, that the frequency of the unbalanced electromagnetic force is high enough to excite several vibration modes of the rotor. Harmonic analyses performed in the case of electromagnetic unbalance have shown a relatively high level of velocity amplitudes. However, it should be noticed that the vibration analyses were carried out under the worst-case scenario - that with the maximal value of radial eccentricity of the rotor and maximal electric torque.

The vibration analyses of the stator revealed that the lowest dominant vibration mode order of the considered motor is the circumferential mode number two. The electromagnetic excitation that was the input to the numerical computations of the housing vibration has been chosen for the following motor working point: coil current equal $I=142$ A, field weakening angle $\gamma=14.4^{\circ}$, and rotor speed $\omega=3600 \mathrm{rpm}$. At this working point, the radial component of the electromagnetic force was expected to reach its maximal value, and therefore classified as the worst case in terms of the amplitude of housing vibration. For this reason, all computed values (especially for rotor speeds greater than $3600 \mathrm{rpm}$ ) are expected to be overestimated. For better assessment of the computation error, a vibration analysis for other motor working points should be done.

The analysis was performed in the case of the rotor placed concentrically in the stator. In reality - mainly because of mechanical tolerances - the rotor eccentricity is expected to reach some hundreds micrometres for this type of motor. An eccentrically placed rotor imposes an inhomogeneous distribution of the electromagnetic force on the stator teeth. To assess the effect of rotor eccentricity, further computation cases are required. 
The analysis was performed for rotor speeds ranging from 60 to $12,960 \mathrm{rpm}$ (with a computation step of $60 \mathrm{rpm}$ ) and was restricted to 50 harmonic components $(n=50)$. The total number of computation points was set to 10,750 . In order to find the influence of other harmonic components, one should increase parameter $n$. One should especially assess the effect of $n=64$ and $n=80$.

\section{Acknowledgements}

The work has been performed as a part of the MotorBrain project, co-funded by grants from the ENIAC member states and the ENIAC Joint Undertaking.

\section{References}

Arata M., Takahashi N., Fujita M., Mochizuki M., Araki T., Hanai T., 2012, Noise lowering for a large variable speed range use permanent magnet motor by frequency shift and structural response evaluation of electromagnetic forces. Journal of Power Electronics 12(1), 67-74.
Brockerhoff P., Burkhardt Y., Ehlgen T., Lucas P., 2013, Electrical drive train without rare earth magnets and integrated inverter with inherent redundancy. Electric Drives Production Conference and Exhibition.

Islam M., Husain I., 2010, Analytical model for predicting noise and vibration in permanent-magnet synchronous motors. IEEE Transactions on Industry Applications 46(6), 2346-2354.

Miller T.J., McGilp M., 2009, Analysis of multi-phase, permanent-magnet synchronous machines. International Conference on Electrical Machines and Systems (ICEMS), 15-18 November. MotorBrain, http://www.motorbrain.eu/ abgerufen (21.04.2016).

Pellerey P., Lanfranchi V., Friedrich G., 2012, Coupled numerical simulation between electromagnetic and structural models influence of the supply harmonics for synchronous machine vibrations. IEEE Transactions on Magnetics 48(2), 983-986.

Rahman K., Anwar M., Schulz S., 2011, The Voltec 4 ET50 electric drive system. SAE International Journal of Engines 4(1), 323-337.

Zhu Z., Xia Z., Wu L., Jewell G., 2010, Analytical modeling and finite-element computation of radial vibration force in fractional-slot permanent-magnet brushless machines. IEEE Transactions on Industry Applications 46(5), 1908-1918. 